\title{
Immunological recovery in tuberculosis/HIV co-infected patients on antiretroviral therapy: implication for tuberculosis preventive therapy
}

Basel Karo ${ }^{1,2^{*}}$, Gérard Krause ${ }^{3,4}$, Stefanie Castell ${ }^{3}$, Christian Kollan' ${ }^{1}$ Osamah Hamouda', Walter Haas ${ }^{1}$ and the ClinSurv HIV Study Group

\begin{abstract}
Background: Understanding the immune response to combination antiretroviral therapy (CART) is essential for a clear approach to tuberculosis (TB) preventive therapy. We investigated the immunological recovery in cART-treated HIV-infected patients developing TB compared to those who remained free of TB.

Methods: We extracted data of HIV-infected patients from a multicenter cohort for the HIV clinical surveillance in Germany. No patients included in our study had TB at the beginning of the observation. Using a longitudinal mixed model, we assessed the differences in the mean change of biomarkers (CD4+ cell count, CD8+ cell count, CD4:CD8 ratio and viral load) since CART initiation in patients who remained free of TB vs. those developing TB. To detect the best-fit trajectories of the immunological biomarkers, we applied a multivariable fractional polynomials model.

Results: We analyzed a total of 10,671 HIV-infected patients including 139 patients who developed TB during follow-up. The highest TB incidences were observed during the first two years since CART initiation ( 0.32 and 0.50 per 100 personyears). In an adjusted multivariable mixed model, we found that the average change in CD4+ cell count recovery was significantly greater by 33 cells $/ \mu$ in patients who remained free of TB compared with those developing TB. After the initial three months of CART, $65.6 \%$ of patients who remaining free of TB achieved CD4+ count of $\geq 400$ cells/ $\mu$, while only $11.3 \%$ of patients developing TB reached this immunological status after the three months of CART. We found no differences in the average change of CD8+ cell count, CD4:CD8 ratio or viral load between the two-patient groups.
\end{abstract}

Conclusion: All HIV-infected patients responded to CART. However, patients developing TB showed reduced recovery in CD4+ cell count and this might partly explain the incident TB in HIV-infected patients receiving CART. These findings reinforce the importance of adjunctive TB preventive therapy for patients with reduced recovery in CD4+ cell count.

Keywords: HIV/aids, Tuberculosis, Antiretroviral therapy, Immune recovery, Developed country

\footnotetext{
* Correspondence: karob@rki.de; baselkaro@gmail.com

Preliminary results from this study were presented in the HIV-TB late-breaker session at The 47th Union World Conference on Lung Health; October 26-29, 2016, Liverpool, United Kingdom.

'Department for Infectious Disease Epidemiology, Robert Koch Institute (RKI),

Seestr. 10, 13353 Berlin, Germany

${ }^{2}$ PhD Programme, "Epidemiology", Braunschweig-Hannover, Germany

Full list of author information is available at the end of the article
}

\section{Biomed Central}

(c) The Author(s). 2017 Open Access This article is distributed under the terms of the Creative Commons Attribution 4.0 International License (http://creativecommons.org/licenses/by/4.0/), which permits unrestricted use, distribution, and reproduction in any medium, provided you give appropriate credit to the original author(s) and the source, provide a link to the Creative Commons license, and indicate if changes were made. The Creative Commons Public Domain Dedication waiver (http://creativecommons.org/publicdomain/zero/1.0/) applies to the data made available in this article, unless otherwise stated. 


\section{Background}

Infection with HIV is the most potent risk factor for tuberculosis (TB) [1]. HIV causes functional and numeric depletion of TB-specific lymphocytes, leading to impairment of both cell-mediated immune response, and granuloma formulation and maintenance [2]. Therefore, co-infection with HIV increases the risk of progression to active $\mathrm{TB}$, and reactivation of latent $\mathrm{TB}$ infection (LTBI) [3]. The introduction of combination antiretroviral therapy (cART) in the mid-1990s has markedly reduced HIVrelated morbidity, and mortality [4]. Although cART is associated with a dramatic decline in TB risk by $70 \%-90 \%$ among HIV-infected patients [5], TB incidence remains elevated in settings with high $[5,6]$ and low TB incidence $[5,7]$. Empirical observations and modelling studies suggests that cART may have limited long-term impact on TB incidence at a population level [8]. Also, HIV infection was associated with lower TB treatment success rates even in settings with available cART $[9,10]$.

TB preventive therapy can significantly reduce the risk of TB among HIV-infected patients, even among those receiving cART, and living in areas with low TB rates $[11,12]$. Recently, TB preventive therapy for high-risk groups including HIV-infected patients has attracted increasing attention in developed countries, as WHO launched a new action framework towards TB elimination in low incidence countries [13]. It is recommended that preventive therapy should be offered to HIV-positive patients particularly for those with positive tuberculin skin tests (TST) $[11,12]$. Such an approach has limitations due to the low sensitivity of TST among HIV-infected patients [14]. It has been observed that the proportion of TSTpositive results is associated with higher CD4+ cell count, and TST-negative HIV-infected patients could still develop active TB $[15,16]$. The greater the immunosuppression, the lower the probability of positive skin reaction $[14,17]$. This means that there is an increased risk that HIV-infected patients most in need will be left without preventive therapy. Similarly, interferon-gamma release assays (IGRAs) have clearly low sensitivity in HIV-positive patients and do not offer any advantage over TST [18]. A multicenter European study (TBNET Study) showed that progression towards active TB in immunocompromised patients was poorly predicted by TST or IGRAs [19].

The majority of studies defined HIV-infected patients at high risk for $\mathrm{TB}$ and, therefore, those who might benefit from preventive therapy based on baseline CD4+ cell count $[6,7,20]$. In addition to the lack of consensus on the optimal threshold, this approach does not take into account that TB risk changes over time in association with ART-induced immune recovery. Despite the advances in HIV literature on the immune response to cART, there is still limited information on immune recovery in relation to TB development. Investigating the growth dynamic of immune biomarkers under cART is essential to understand the risk of TB development in cART-treated patients and helps to improve our TB preventive therapy approach.

In this study, we aimed to investigate whether the average change in immunological biomarkers is associated with TB development and to analyze the immunological dynamic in cART-treated HIV-infected patients in relation to development of active TB.

\section{Methods}

\section{Data source and study population}

The study was based on the German ClinSurv HIV Cohort, which is an ongoing open multicentre cohort for the clinical surveillance of HIV in Germany. The ClinSurv HIV cohort was established in 1999 as a collaborative cohort between specialized treatment centres for HIV/AIDS and the Robert Koch Institute. Irrespective of the disease stage, all HIV-infected patients are eligible to attend one of the treatment centres and can be enrolled in the ClinSurv HIV Cohort. The ClinSurv dataset includes basic demographic data recorded anonymously at the first contact. Clinical and laboratory data are collected and updated in 3-monthperiods when data are available. The German ClinSurv HIV Cohort has been described in detail elsewhere [7, 21].

For our analysis, we included patients who started cART between 1999 and 2013. cART was defined as "triple-drug therapy" involving two nucleoside reverse-transcriptase inhibitors (NRTI) plus one non-nucleoside reversetranscriptase inhibitor (NNRTI) or protease inhibitor. We excluded patients who developed TB during the first 3 months after cART initiation. These cases may reflect unmasking active TB known as TB-associated immune reconstruction inflammatory syndrome (TB-IRIS) [22]. These cases are not clinically apparent prior to cART initiation and manifest after the recovery of the immune system induced by HIV therapy [22]. TB cases were defined as any form of TB bacteriologically confirmed or clinically diagnosed.

No patient included in our analysis has received TB preventive therapy during follow-up observation. No data were available on LTBI testing in the German HIV Cohort.

\section{Statistical analysis and modeling approach}

Continuous variables were described using medians, and interquartile ranges (IQR) and compared by a nonparametric K-sample test on the equality of medians. Categorical variables were described using absolute and relative frequencies and compared by the $x^{2}$ test for difference in proportion.

We used a Cox proportional hazards regression model (survival analysis) to estimate the TB incidence rate defined as the number of TB cases occurring per 100 
person-years of observation. The observation period was calculated as the time from cART initiation to either diagnosis of TB, last follow-up, a maximum of a 7-year observation period (very few measurements were available beyond seven years of follow-up) or the last possible observation date (30 June 2014).

We investigated the difference in the mean change of each laboratory measurements (CD4+ cell count, CD8 + cell count, CD4:CD8 ratio, and viral load) overtime on cART between patients remained free of TB vs. those developing TB. Laboratory measurements were coded as time-varying variables and were the main outcome variables. Subjects included in the analysis required at least two serial measurements; measurements taken after TB diagnosis were not included in the analysis. Baseline measurements were defined as the measurements taken at the date of cART initiation. We fitted a separate longitudinal mixed model for each laboratory biomarkers with change since cART initiation at one year interval. The purpose of this approach is to investigate the pattern of the average change in biomarkers over time on cART. We adjusted the models for sex, geographical origin, HIV transmission routes, age, year of cART initiation and baseline value of biomarkers (CD4+ cell count, CD8+ cell count, and viral load). The models were corrected with a random intercept and random slope to account for both individual differences in the average change in immune recovery and individual differences in trajectories across the time of the study. A variance-covariance structure was specified to account for the potential correlation between repeated measurements for the same individuals. Moreover, we added an interaction term between $\mathrm{TB}$ and time on cART to compare the trajectory of change between patients remained free of $\mathrm{TB}$ with those developing TB.

To analyze the growth dynamics of the laboratory biomarkers over time on cART, we used multivariable fractional polynomials (MFP) to account for nonlinear association and to detect the best-fit model [23]. The MFP approach was adjusted for sex, geographical origin, HIV transmission routes, age, year of cART initiation and involves three steps: (1) test of covariates inclusion by backward elimination at a $p$-value of $<0.1,(2)$ test of non-linearity at a $p$ value of $<0.05$, (3) test of simplicity of power transformation (first degree FP vs. second degree FP) at a $p$-value of $<0.05$. Parameters in the final model were estimated using the generalized estimating equations (GEE) method. We used the GEE method to account for possible correlation among the repeated measurements taken in an individual and to deal with longitudinal data on subjects with unequally spaced and varying number of observations (accounting for missing data). All analyses were performed using STATA (version 14, StataCorp, LP, Texas, USA).

\section{Results}

Characteristics of the study population

From January 1999 through December 2013, a total of 11,293 HIV-infected patients initiated cART in the German ClinSurv HIV Cohort. Patients known to have TB prior to CART $(N=371)$, diagnosed with TB within the initial 3 months of cART $(N=86)$, or with less than two available serial laboratory measurements (165) were excluded from our analysis. The majority of HIVinfected patients remaining in our study $(N=10,671)$ were male $(77.4 \%)$, originated from Germany (69.8\%), and had a median age of 38 years at the time of cART initiation. The baseline median CD4+ count was 285 cells/ $\mu$ l [IQR 172 - 413], the baseline median CD8+ count was 896 cells/ $\mu$ l [IQR 603 - 1301], the baseline median CD4:CD8 ratio was 0.3 [IQR $0.2-0.5$ ], and the baseline viral load was $4.6 \log _{10}$ copies/ml [IQR $3.6-$ 5.2]. A total of 139 (1.3\%) patients developed TB during 43,854 person-years follow-up (incidence of 0.32 per 100 person-years of follow-up; 95\% confidence interval (CI) $0.27-0.37)$. Higher incidences were observed during the first two years since cART initiation (1.2 and 0.5 per 100 person-years respectively) (Fig. 1). Differences in demographic and clinical characteristic between patients who remained free of $\mathrm{TB}$ and those developing $\mathrm{TB}$ are presented in Table 1.

\section{Trend of change in biomarkers since CART initiation in relation to tuberculosis}

In a mixed model with adjustment for sex, geographical origin, HIV transmission routes, age, year of cART initiation and baseline value of biomarkers (CD4+ cell count, CD8+ cell count, and viral load), the recovery of biomarkers over time on cART (increasing in CD4+ cell

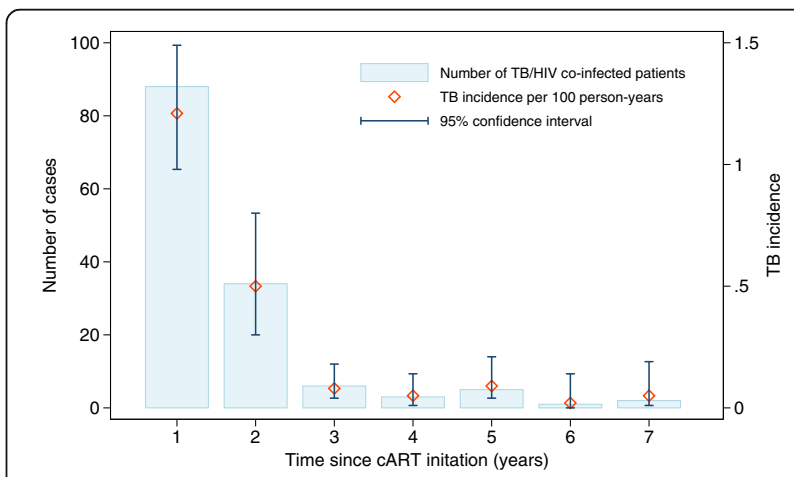

Fig. 1 Tuberculosis incidence among HIV-infected patients since CART initiation in the German ClinSurv HIV cohort, 1999-2013. TB cases diagnosed within the first three months of CART initiation were excluded. CART: combination antiretroviral therapy 
Table 1 Characteristic of CART-treated HIV-infected patients in the German ClinSurv HIV Cohort, 1999-2013

\begin{tabular}{|c|c|c|c|}
\hline $\begin{array}{l}\text { Demographic and clinical characteristic of HIV } \\
\text { patients, } N=10,671(100 \%)\end{array}$ & $\begin{array}{l}\text { HIV-infected patients who remained free of TB, } \\
N=10,532(98.7 \%)\end{array}$ & $\begin{array}{l}\text { HIV-infected patients developing TB, } \\
N=139(1.3 \%)\end{array}$ & $P$ value \\
\hline Female sex & $2388(22.5 \%)$ & $45(31.5 \%)$ & $0.01^{b}$ \\
\hline \multicolumn{4}{|l|}{ Age at time of CART initiation } \\
\hline Median (IQR), years & $38.0(31-45)$ & $36.5(31-45)$ & $0.8^{c}$ \\
\hline \multicolumn{4}{|l|}{ Geographical origin } \\
\hline Germany & 7289 (70.1\%) & $60(42.9 \%)$ & \multirow[t]{4}{*}{$<0.001^{\mathrm{b}}$} \\
\hline Sub-Saharan Africa & $1344(12.9 \%)$ & $50(35.7 \%)$ & \\
\hline South-/Southeast Asia & $273(2.7 \%)$ & $10(7.1 \%)$ & \\
\hline Others & $1486(14.3 \%)$ & $20(14.3 \%)$ & \\
\hline \multicolumn{4}{|l|}{ HIV-transmission routes } \\
\hline MSM & $5377(56.9 \%)$ & 49 (36.6\%) & \multirow[t]{3}{*}{$<0.001^{\mathrm{b}}$} \\
\hline IDUs & $886(9.4 \%)$ & $8(6.0 \%)$ & \\
\hline Others & 3186 (33.7\%) & $77(57.4 \%)$ & \\
\hline \multicolumn{3}{|l|}{ Calendar year of CART initiation } & \multirow[t]{4}{*}{$<0.001^{\mathrm{b}}$} \\
\hline 1999-2002 & 2524 (23.9\%) & $56(24.2 \%)$ & \\
\hline 2003-2008 & $4531(43.1 \%)$ & $58(43.0 \%)$ & \\
\hline $2009-2013$ & 3477 (33.0\%) & $25(32.8 \%)$ & \\
\hline \multicolumn{4}{|l|}{ Baseline CD4+ count ${ }^{a}$} \\
\hline Median (IQR), cells per $\mu \mathrm{l}$ & $285(173-413)$ & $168(80-326)$ & $0.1^{c}$ \\
\hline \multicolumn{4}{|l|}{ Baseline CD8+ count $^{\mathrm{a}}$} \\
\hline Median (IQR), cells per $\mu \mathrm{l}$ & $900(602-1297)$ & $846(609-1364)$ & $0.8^{c}$ \\
\hline \multicolumn{4}{|l|}{ Baseline CD4:CD8 ratio $^{a}$} \\
\hline Median (IQR) & $0.3(0.2-0.5)$ & $0.2(0.1-0.3)$ & $0.3^{c}$ \\
\hline \multicolumn{4}{|l|}{ Baseline viral load ${ }^{a}$} \\
\hline Median (IQR), $\log _{10}$ copies per $\mathrm{ml}$ & $4.6(3.6-5.2)$ & $4.9(3.7-5.1)$ & $0.06^{c}$ \\
\hline
\end{tabular}

CART combination antiretroviral therapy, TB tuberculosis, IQR interquartile range, MSM men who have sex with men, IDU injecting drug users

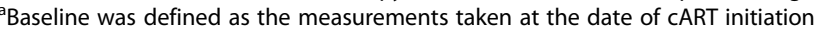

${ }^{b}$ Obtained using a $x^{2}$ test for difference in proportion

'Obtained using a non-parametric K-sample test on the equality of medians

count and CD4:CD8 ratio; decreasing in CD8+ cell count and viral load) was significant for all investigated biomarkers and irrespective to TB (Table 2) (Fig. 2). However, patients remaining free of TB had significantly a more marked increase in the change of CD4+ cell count since cART initiation than those developing TB. No significant difference in the pattern of change for CD8+ cell count, CD4:CD8 ratio or viral load was observed between the two-patient groups (Table 2) (Fig. 2).

\section{Growth dynamics of CD4+, CD8+, CD4:CD8 ratio, and viral load}

After cART initiation, the general pattern of the CD4+ cell count was increasing over time but at a decreasing rate. Compared to patients remaining free of $\mathrm{TB}$, patients developing TB showed less marked increase in CD4+ cell count over time $(P<0.001)$ (Fig. 3a). After the initial 3 months of cART, $65.6 \%$ of patients who remaining free of TB achieved CD4+ count of $>400$ cells $/ \mu \mathrm{l}$, while just $11.3 \%$ of patients developing $\mathrm{TB}$ reached this status within the same period (corresponding to $60 \%$ vs. $25 \%$ increase in CD4 cell counts compared to the baseline values respectively). Similarly, the general pattern of CD4:CD8 ratio improved substantially over time; again patients who remained free of TB showed faster recovery compared to patients developing $\mathrm{TB}$ $(P<0.001)$ (Fig. 3c). After the initial phase, patients remaining free of $\mathrm{TB}$ reached on average a 0.44 CD4:CD8 ratio, which was achieved by $56.1 \%$ of them vs. $8.3 \%$ of patients developing TB.

In the initial 3 months of cART, CD8+ cell count showed a sharp rise followed by a sharp decline reaching approximately 1100 cell/ $\mu \mathrm{l}$ after 3 months of cART. Afterwards, CD8+ cell count decreased slowly over time. No significant difference was observed in the dynamics of CD8+ cell count in relation to development of active TB $(P=0.48)$ (Fig. 2b). HIV viral load showed a sharp drop in the initial phase of cART 
Table 2 Change in biomarkers since CART initiation among HIV-infected patients in the ClinSurv HIV cohort, 1999-2013

\begin{tabular}{|c|c|c|}
\hline Biomarkers & Estimated change over time on CART (per year) & $P$ value \\
\hline CD4+ count & 43.9 cells per $\mu$ l (95\% Cl 43.1 to 44.6$)$ & $<0.001$ \\
\hline CD8+ count & -27.9 cells per $\mu \mathrm{l}(95 \% \mathrm{Cl}-28.6$ to -27.2$)$ & $<0.001$ \\
\hline CD4:CD8 ratio & 0.06 (95\% 0.06 to 0.07$)$ & $<0.001$ \\
\hline Viral load & $-0.1 \log _{10}$ copies per $\mathrm{ml}(95 \% \mathrm{Cl}-0.1$ to -0.1$)$ & $<0.001$ \\
\hline Biomarkers & $\begin{array}{c}\text { Estimated mean of difference in change of } \\
\text { biomarkers between cART-treated patients } \\
\text { developing TB vs. those who remained free of } \\
\text { TB }\end{array}$ & $P$ value \\
\hline CD4+ count & -33 cells per $\mu \mathrm{l}(95 \% \mathrm{Cl}-44.6$ to 21.2$)$ & 0.001 \\
\hline CD8+ count & -72 cells per $\mu \mathrm{l}(95 \% \mathrm{Cl}-84.6$ to 1.7$)$ & 0.1 \\
\hline CD4:CD8 ratio & $-0.01(95 \% \mathrm{Cl}-0.03$ to 0.01$)$ & 0.2 \\
\hline Viral load & $0.01 \log _{10}$ copies per $\mathrm{ml}(-0.04$ to 0.06$)$ & 0.7 \\
\hline
\end{tabular}

CART combination antiretroviral therapy, TB tuberculosis, IQR interquartile range Longitudinal mixed models adjusted for sex, geographical origin, HIV transmission routes, age, year of CART initiation and baseline value of biomarkers (CD4+ count $\mathrm{CD} 8+$ count, and viral load) and including interaction term between time and TB

reaching approximately $2.5 \log _{10}$ copies $/ \mathrm{ml}$ followed by a plateau (Fig. 3d). Patients who remained free of TB had a plateau at a significantly lower level compared to those developing TB (Fig. 3d). We applied piecewise-linear trend models to assess the nonlinearity and patterns of change of biomarkers and it confirmed our findings and showed no significant differences from the trajectories obtained by the MPF models (data not shown).

\section{The trend of CD4+ cell count close to the time of tuberculosis diagnosis}

Using a fractional polynomial fit, we observed a decline in CD4+ cell count around 5 months before TB diagnosis. However, this pattern in CD4+ cell count did not show a significant drop since the fractional polynomial growth does not fit the data significantly better than the linear fit (deviance difference $=0.89 ; P=0.8$ ). In the linear regression model adjusted for sex, geographical origin, HIV-transmission routes, age, and year of cART initiation, CD4+ cell count continued to recover over time irrespective of the time of TB diagnosis [RC 0.07 CI $0.004-0.14, P=0.04]$. We could not investigate how the trend of viral load, CD8+ cell count, and CD4:CD8 ratio developed at the time close to $\mathrm{TB}$ diagnosis as there were insufficient measurements of these variables around the time of TB diagnosis.

\section{Discussion}

We investigated the immunological recovery in cARTtreated HIV-infected patients in the German HIV cohort in relation to development of active TB. Although patients developing $\mathrm{TB}$ showed effective response to cART, we found that the average change of increases in CD4+ count was significantly smaller by 33 cells $/ \mu$ l compared with patients who remained free of TB. After the initial 3 months of cART, $65.6 \%$ of patients who remaining free of $\mathrm{TB}$ achieved CD $4+$ count of $>400$ cells $/ \mu$ l, while just $11.3 \%$ of patients developing TB reached this status within the a
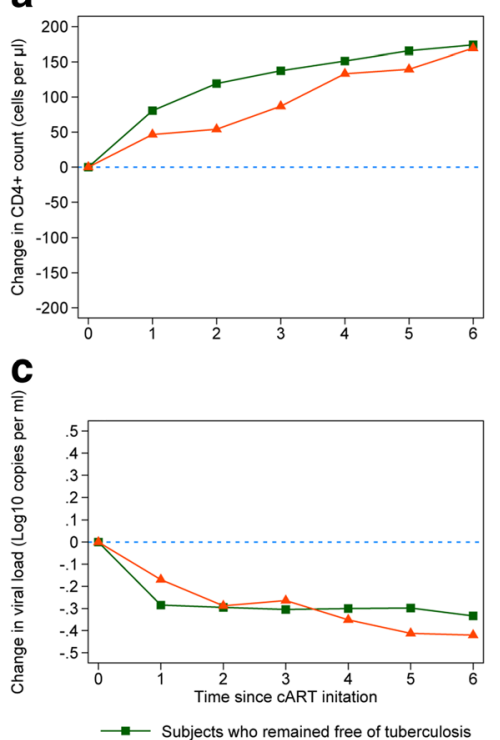

b
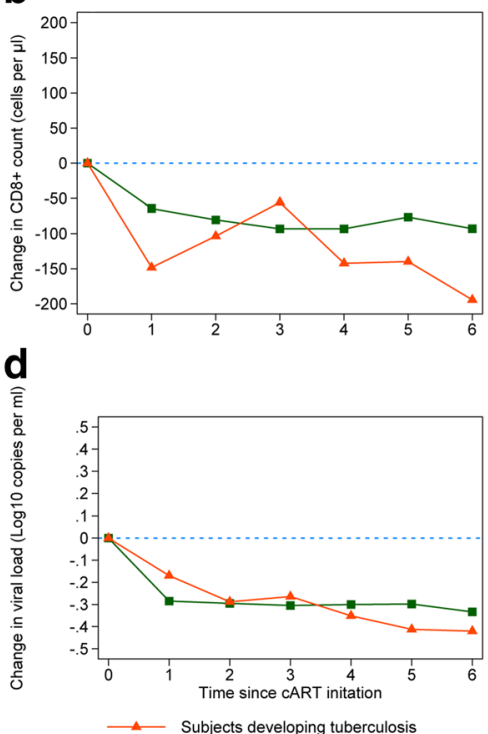

Fig. 2 Change in biomarkers since CART initiation among HIV-infected patients in the ClinSurv HIV cohort, 1999-2013. (a) Change in CD4+ cell count. (b) Change in CD8+ cell count. (c) Change in CD4:CD8 ratio. (d) Change in viral load 

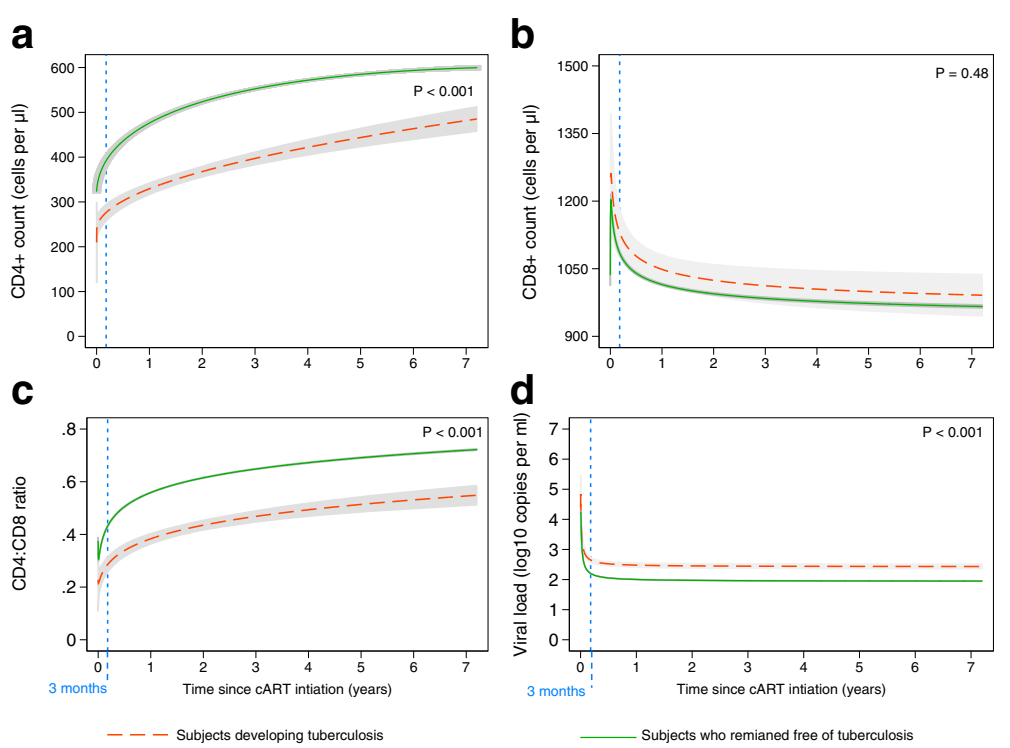

Fig. 3 Immunological recovery since CART initiation among HIV-infected patients in the German ClinSurv HIV Cohort, 1999-2013. (a) Profile plot of CD4+ cell count. (b) Profile plot of CD8+ cell count. (c) Profile plot of CD4:CD8 ratio. (d) Profile plot of viral load. The best-fitting model of CD4+ cells count is FP2 $(0,0.5)$ for subjects who remained free of TB and is FP2 $(-1,1)$ for subjects who developed TB. Irrespective to TB development, the best-fitting model of CD8+ cells count is FP2 $(-0.5,-0.5)]$, of CD4:CD8 ratio is FP2 $(-0.5,-0.5)$, and of viral load is FP2 $(-2,-0.5)$. No measurements were included after TB diagnosis. TB: tuberculosis; FP2: second-degree fractional polynomial model

same period. We found no differences in the change of CD8+ cell count, CD4:CD8 ratio or viral load between the two-patient groups.

Excess TB rates during early cART were observed in many studies and were attributed to cART-induced unmasking of subclinical TB $[7,24]$. However, we still found a higher TB incidence in the first year of cART in our study population, even after excluding cases that occurred in the first 3 months of cART. The mechanisms underlying development of $\mathrm{TB}$ in this period are not fully understood and reflect a spectrum of complex interactions between mycobacterial antigen load and cART-induced immune response [22, 25-27]. Given the risk of subsequent transmission due to unrecognized active $\mathrm{TB}$ and the high disease burden of unmasked TB, all possible efforts are needed to prevent it. Early initiation of cART before significant immune depletion will potentially decrease the risk of unmasking TB $[26,27]$.

In our data, patients developing TB started cART at lower CD4+ cell count compared to patients remaining free of TB. Despite not being statistically significant, this lower baseline count may reflect a greater degree of pre-treatment immunodeficiency, requiring for patients developing TB a more prolonged treatment period for CD4+ cell count to recover [28] and therefore could partially explain the reduced recovery among them. Different studies done in high and low income countries showed that baseline CD4+ cell count was independently associated with higher risk of TB $[6,7,20]$. However, the increase of CD4
+ cell count remained significantly greater in patients who remained free of TB after controlling for baseline biomarkers. This different increase in CD4+ cell count might partially explain the risk of TB in cART-treated HIVinfected patients. These results are supported by findings from a current study that showed that bacterial infections in HIV-infected people was associated with change in CD + cell count since study entry [29]. Other studies showed that baseline CD4+ cell count did not have any predictive value for TB risk after controlling for the updated CD4+ cell count [30,31].

The overall recovery of CD4+ cell count in the first 3 months of cART was relatively rapid, and then continued to rise at a slower rate. This is consistent with other findings from HIV studies that show rapid increases in CD4+ cell count among cART-treated patients predominantly occur in the first months with comparatively smaller gains thereafter [32-35]. Importantly, patients developing TB lacked comparable immune recovery and spent a substantial time at lower $\mathrm{CD} 4+$ cell count and showed smaller increase in $\mathrm{CD} 4+$ count. Therefore they remained at high TB risk for a long period of time and this was mirrored by the higher TB incidence occurring during this period. Immunological studies suggest that full restoration of lymphocytes only occurs in a minority of cART-treated patients and longterm recovery of TB-specific immune function remains incomplete despite continuous suppression of HIV replication $[36,37]$. This hinders the extent to which cART can contribute to TB control [37]. 
Isoniazid preventive therapy (IPT) is the most widely used regimen and is strongly recommended by WHO to decrease the burden of TB in HIV-infected patients. TB preventive therapy can significantly reduce the risk of TB among HIV-infected patients, even among those receiving cART, and living in areas with low TB rates. However, implementation of IPT at the same time as ART may be problematic due to the difficulty in excluding active $\mathrm{TB}$ at baseline and unmasking $\mathrm{TB}$ during the first months of ART. Furthermore, inadequate patient adherence to IPT and fear of promoting resistance to isoniazid through IPT represent other major barriers to IPT implementation [38]. Different studies have suggested the use of preventive therapy not only at baseline but also serially or continuously for patients at higher risk of TB $[29,39]$. Our data add strong evidence to use immune recovery to identify patients who could benefit from adjunctive TB preventive therapy even if they initially respond to cART. In light of our findings, a logical approach might be to wait 3 months after cART initiation in order to exclude unmasking TB and then consider TB preventive therapy for patients with reduced immune recovery. A prospective study is required to confirm these findings and to identify a threshold of $\mathrm{CD} 4+$ cell count blow which preventive therapy should be considered in comparison to a LTBI testing approach.

Similar to CD4+ cell count, CD4:CD8 ratio in patients developing TB relatively recovered at a lower rate. Other studies have shown that despite effective cART and CD4+ recovery above 500 cells/ $\mu \mathrm{l}$, a persistently low CD4:CD8 ratio acts as a marker of continuing immune dysfunction [40], and the onset of HIV-related diseases [41]. However, controlling for baseline biomarkers revealed no significant difference in the average change of $\mathrm{CD} 4: \mathrm{CD} 8$ ratio over time on cART.

We found that irrespective of TB progression, CD8+ cells count increased markedly in the initial weeks of cART, followed by a significant decrease and subsequent plateau for the rest of follow-up. Elevation of CD8+ cell count occurs in the very early days of HIV infection as a general reaction to viral infections [42]. Sharp falls in CD8+ cell count can be observed shortly after the initiation of cART but CD8+ cell count remain persistently elevated during HIV infection and do not normalize despite long-term cART $[42,43]$. It is well-known that CD8+ cells play an important role in the elimination of both TB- and HIV-infected cells and consequent immune control. Dysmature CD8+ cells are a common phenomenon in HIV-infected patients; these $\mathrm{CD} 8+$ cells produce significantly lower levels of perforin, granulysin, and TNF- $\alpha$ which are crucial components of a protective immune response to $\mathrm{TB}$ infection [42]. Again these facts highlight the limitation of cART in TB prevention in HIV-infected patients.

HIV viral load plateaued rapidly after a steep decline in the initial 3 months of cART in both patients developing TB and those who remained free of TB. However, a higher level of viral load persisted among patients developing $\mathrm{TB}$ compared to those who remained free of TB. This might reflect the differences in growth dynamic of $\mathrm{CD} 4+$ cell count between them, where restoration of $\mathrm{CD} 4+$ cell count is associated with the degree of suppression of HIV replication.

Interestingly, our data showed a decline in CD4+ cell count close to the time of TB diagnosis (around 5 months prior). However, this finding was not statistically significant and needs to be repeated with a larger sample size in order to investigate the usefulness of a drop in CD4+ cell count in predicting the onset of active TB. This hypothesis is supported by the fact that depletion of $\mathrm{CD} 4+$ cell count impairs cell-mediated immune responses, and granuloma formation and function leading to an increased risk of active TB [2].

There are some limitations to this study. Our analyses involved relatively few TB events $(n=139)$, which might limits the study power. We could not investigate the trend of $\mathrm{CD} 8+$ cell count, and viral load close to TB diagnosis due to missing data. It is unknown whether TB diagnosis was systematically performed among all HIV-infected patients in the ClinSurv HIV Cohort (active case finding) or whether it was just a part of on-going health care (passive case finding); therefore some $\mathrm{TB}$ cases may not have been detected. The success rate of and adherence to cART may play role in the immunological response and it was not included in our analysis due to lack of data. However, current study on the ClinSurv HIV cohort showed that around $95 \%$ of the patients in the cohort achieve viral suppression (viral load $<50$ copies $/ \mathrm{ml}$ ), suggesting a high success rate and adherence to cART among patients [44].

\section{Conclusion}

Our findings highlight the strong association between TB and the cART-induced response of CD4+ cell count in HIV-infected patients. Although the initially response to cART was observed, patients developing TB showed reduced cART-induced increases in CD4+ cell count. This might partly explain the incident $\mathrm{TB}$ in HIV-infected patients receiving cART. These findings reinforce the importance of adjunctive TB preventive therapy for those patients with reduced recovery in $\mathrm{CD} 4+$ cell count. Prospective studies are needed to confirm protective 
immunological thresholds for TB with an adequate assessment of cART adherence.

\begin{abstract}
Abbreviations
CART: Combination antiretroviral therapy; GEE: Generalized estimating equations.; IQR: Interquartile ranges; MFP: Multivariable fractional polynomial; NNRTI: Non-nucleoside reverse-transcriptase inhibitor; NRTI: Nucleoside reverse-transcriptase inhibitors; TB: Tuberculosis; TB-IRIS: TB-associated immune reconstruction inflammatory syndrome; TST: Tuberculin skin test
\end{abstract}

\section{Acknowledgements}

The authors are grateful to the patients who joined the ClinSurv HIV cohort. Also, the authors would like to acknowledge Matthias an der Heiden for valuable discussion and advice on parts of the statistical analysis.

The German ClinSurv HIV Study Group: Berlin: Robert Koch Institute: A. Kühne (Cohort manager); Vivantes Auguste-Viktoria-Hospital: K. Arastéh; Charité University Medicine: F. Bergmann, M. Warncke; Bonn: University Hospital: J. Rockstroh, J. Wasmuth, S. Hass; Düsseldorf: University Hospital Düsseldorf: B. Jensen, C. Feind; Essen: University Hospital Essen: S. Esser, P. Schenk-Westkamp; Frankfurt: HIV Centre Frankfurt, C. Stephan, A. Haberl, P. Schott; Hamburg: ifi-Institute for Interdisciplinary Medicine; A. Plettenberg, F. Kuhlendahl; ICH Studycenter: H.-J. Stellbrink, A. Adam, K. Schewe, S. Fenske, T. Buhk, C. Hoffmann, D. Radzuweit, A. Mainka; University Hospital Eppendorf: O. Degen, M. Franz, N. Treffler; Hanover: Medical University Hanover: M. Stoll, R. Beider S. Gerschmann, K. Hoeper; Kiel: University Schleswig-Holstein, Campus Kiel: H.A. Horst, S. Trautmann; Cologne: University Hospital Cologne: G. Fätkenheuer, D. Gillor; Munich: University Hospital, Ludwig-Maximilian University: J. Bogner, B. Sonntag; Regensburg: University Hospital Regensburg: B. Salzberger; Rostock: University Hospital Rostock: C. Fritzsche.

\section{Funding}

No external funding was received for this project.

\section{Availability of data and materials}

The datasets analyzed during the current study are not publicly available due to the respect and protection of privacy of the patients, but are available from the corresponding author on reasonable request.

\section{Authors' contributions}

Concept and design (BK, WH), literature search (BK), data extraction and acquisition (CK), statistical analysis (BK), interpretation of the data (BK, WH, GK, SC), drafting the manuscript (BK) and critical revision of the manuscript for important intellectual content (BK, WH, GK, SC, OH, CK). All authors read and approved the final manuscript.

\section{Ethics approval and consent to participate}

The ClinSurv HIV study protocol was approved by the German Federal Commissioner for Data Protection and Freedom of Information. No separate ethical approval or additional permission is required for secondary analysis of the study data due to the anonymous nature of the data.

\section{Consent for publication}

Not applicable.

\section{Competing interests}

The authors declare that they have no competing interests.

\section{Publisher's Note}

Springer Nature remains neutral with regard to jurisdictional claims in published maps and institutional affiliations.

\section{Author details}

'Department for Infectious Disease Epidemiology, Robert Koch Institute (RKI), Seestr. 10, 13353 Berlin, Germany. ${ }^{2}$ PhD Programme, "Epidemiology", Braunschweig-Hannover, Germany. ${ }^{3}$ Department of Epidemiology, Helmholtz Centre for Infection Research (HZI), Braunschweig, Germany. ${ }^{4}$ Hannover Medical School (MHH), Hannover, Germany.
Received: 13 April 2017 Accepted: 21 July 2017

Published online: 25 July 2017

\section{References}

1. Lawn SD, Zumla Al. Tuberculosis. Lancet. 2011;378(9785):57-72.

2. Lawn SD, Butera ST, Shinnick TM. Tuberculosis unleashed: the impact of human immunodeficiency virus infection on the host granulomatous response to mycobacterium tuberculosis. Microbes Infect. 2002;4(6):635-46.

3. Djoba Siawaya JF, Ruhwald M, Eugen-Olsen J, Walzl G. Correlates for disease progression and prognosis during concurrent HIV/TB infection. Int J Infect Dis. 2007;11(4):289-99.

4. Palmisano L, Vella S. A brief history of antiretroviral therapy of HIV infection: success and challenges. Ann Ist Super Sanita. 2011;47(1):44-8.

5. Lawn SD, Wood R. Incidence of tuberculosis during highly active antiretroviral therapy in high-income and low-income countries. Clin Infect DisClin Infect Dis. 2005;41(12):1783-6.

6. Lawn SD, Badri M, Wood R. Tuberculosis among HIV-infected patients receiving HAART: long term incidence and risk factors in a south African cohort. AIDS. 2005;19(18):2109-16.

7. Karo B, Haas W, Kollan C, Gunsenheimer-Bartmeyer B, Hamouda O, Fiebig L. German ClinSurv HIV study group. Tuberculosis among people living with HIV/AIDS in the German ClinSurv HIV cohort: long-term incidence and risk factors. BMC Infect Dis. 2014;14:148

8. Lawn SD, Harries AD, Williams BG, Chaisson RE, Losina E, De Cock KM, et al. Antiretroviral therapy and the control of HIV-associated tuberculosis. Will ART do it? Int J Tuberc Lung Dis. 2011;15(5):571-81.

9. Karo B, Krause G, Hollo V, van der Werf MJ, Castell S, Hamouda O, Haas W. Impact of HIV infection on treatment outcome of tuberculosis in Europe. AIDS. 2016;30(7):1089-98.

10. King L, Munsiff SS, Ahuja SD. Achieving international targets for tuberculosis treatment success among HIV-positive patients in new York City. Int J Tuberc Lung Dis. 2010;14(12):1613-20.

11. Golub JE, Saraceni V, Cavalcante SC, Pacheco AG, Moulton LH, King BS, Efron A, Moore RD, Chaisson RE, Durovni B. The impact of antiretroviral therapy and isoniazid preventive therapy on tuberculosis incidence in HIVinfected patients in Rio de Janeiro Brazil. AIDS. 2007;21(11):1441-8.

12. Akolo C, Adetifa I, Shepperd S, Volmink J. Treatment of latent tuberculosis infection in HIV infected persons. Cochrane Database Syst Rev. 2010;1:CD000171.

13. World health Organization. Towards TB elimination: an action framework for low-incidence countries. WHO/HTM/TB/2014.13. Geneva: World Health Organization; 2014. Available at http://www.who.int/tb/publications/ elimination_framework/en/. Accessed 18 May 2016.

14. Cobelens FG, Egwaga SM, van Ginkel T, Muwinge H, Matee MI, Borgdorff MW. Tuberculin skin testing in patients with HIV infection: limited benefit of reduced cutoff values. Clin Infect Dis. 2006;43(5):634-9.

15. Martín-Echevarria E, Rodríguez-Zapata M, Torralba M, Fernández JM, Moreno A Casado JL, Dronda F, Pérez-Elías MJ, Navas E, Moreno S. Incidence of tuberculosis in HIV-infected patients receiving HAART: interaction between TST and CD4 count. Int J Tuberc Lung Dis. 2011;15(10):1347-52.

16. Martínez-Pino I, Sambeat MA, Lacalle-Remigio JR. Domingo P; VACH cohort study group. Incidence of tuberculosis in HIV-infected patients in Spain: the impact of treatment for LTBI. Int J Tuberc Lung Dis. 2013;17(12):1545-51.

17. Duncan LE, Elliott AM, Hayes RJ, Hira SK, Tembo G, Mumba GT, et al. Tuberculin sensitivity and HIV-1 status of patients attending a sexually transmitted diseases clinic in Lusaka, Zambia: a cross-sectional study. Trans Roy Soc Trop Med Hyg. 1995;89:37-40.

18. Cattamanchi A, Smith R, Steingart KR, Metcalfe JZ, Date A, Coleman C Marston BJ, Huang L, Hopewell PC, Pai M. Interferon-gamma release assays for the diagnosis of latent tuberculosis infection in HIV-infected individuals: a systematic review and meta-analysis. J Acquir Immune Defic Syndr. 2011;56(3):230-8.

19. Sester M, van Leth F, Bruchfeld J, Bumbacea D, Cirillo DM, Dilektasli AG, Domínguez J, Duarte R, Ernst M, Eyuboglu FO, Gerogianni I, Girardi E, Goletti D, Janssens JP, Julander I, Lange B, Latorre I, Losi M, Markova R, Matteelli A, Milburn H, Ravn P, Scholman T, Soccal PM, Straub M, Wagner D, Wolf T, Yalcin A. Lange C; TBNET. Risk assessment of tuberculosis in immunocompromised patients. A TBNET study. Am J Respir Crit Care Med. 2014;190(10):1168-76.

20. Sterling TR, Lau B, Zhang J, Freeman A, Bosch RJ, Brooks JT, Deeks SG, French A, Gange S, Gebo KA, John Gill M, Horberg MA, Jacobson LP, Kirk GD, Kitahata MM, Klein MB, Martin JN, Rodriguez B, Silverberg MJ, Willig JH, Eron JJ, Goedert JJ, 
Hogg RS, Justice AC, RG MK, Napravnik S, Thorne J, Moore RD, North American AIDS Cohort Collaboration on Research and Design (NA-ACCORD) of the International Epidemiologic Databases to Evaluate AIDS (leDEA). Risk factors for tuberculosis after highly active antiretroviral therapy initiation in the United States and Canada: implications for tuberculosis screening. J Infect Dis. 2011;204(6):893-901.

21. Bätzing-Feigenbaum J, Kollan C, Kühne A, Matysiak-Klose D, Gunsenheimer-Bartmeyer B, Hamouda O. ClinSun HIV study group: cohort profile: the German ClinSurv HIV project-a multicentre open clinical cohort study supplementing national HIV surveillance. HIV Med. 2011;12(5):269-78.

22. Lawn SD, Wilkinson RJ, Lipman MC, Wood R. Immune reconstitution and "unmasking" of tuberculosis during antiretroviral therapy. Am J Respir Crit Care Med. 2008;177(7):680-5.

23. Royston P, Sauerbrei W. Multivariable model-building: a pragmatic approach to regression analysis based on fractional polynomials for Modelling continuous variables. Chichester: John Wiley; 2008.

24. Lawn SD, Myer L, Bekker LG, Wood R. Burden of tuberculosis in an antiretroviral treatment programme in sub-Saharan Africa: impact on treatment outcomes and implications for tuberculosis control. AIDS, 2006;20:1605-12.

25. Meintjes G, Lawn SD, Scano F, Maartens G, French MA, Worodria W, Elliott $J H$, Murdoch D, Wilkinson RJ, Seyler C, John L, van der Loeff MS, Reiss P, Lynen L, Janoff EN, Gilks C. Colebunders R; international network for the study of HIV-associated IRIS. Tuberculosis-associated immune reconstitution inflammatory syndrome: case definitions for use in resource-limited settings. Lancet Infect Dis. 2008;8(8):516-23.

26. Manabe YC, Breen R, Perti T, Girardi E, Sterling TR. Unmasked tuberculosis and tuberculosis immune reconstitution inflammatory disease: a disease spectrum after initiation of antiretroviral therapy. J Infect Dis. 2009;199(3):437-44

27. Lapadula G, Soria A, Bandera A, Squillace N, Sabbatini F, Franzetti F, Migliori GB, Gori A. Unmasking tuberculosis in the era of antiretroviral treatment. Eur Respir J. 2012;39(5):1064-75.

28. Kaufmann GR, Bloch M, Finlayson R, Zaunders J, Smith D, Cooper DA. The extent of HIV-1-related immunodeficiency and age predict the longterm CD4 T lymphocyte response to potent antiretroviral therapy. AIDS. 2002;16:359-67.

29. O'Connor J, Vjecha MJ, Phillips AN, Angus B, Cooper D, Grinsztejn B, Lopardo G, Das S, Wood R, Wilkin A, Klinker H, Kantipong P, Klingman KL, Jilich D, Herieka E, Denning E, Abubakar I, Gordin F, Lundgren JD, INSIGHT START study group. Effect of immediate initiation of antiretroviral therapy on risk of severe bacterial infections in HIV-positive people with CD4 cell counts of more than 500 cells per $\mu \mathrm{L}$ : secondary outcome results from a randomised controlled trial. Lancet HIV. 2017;4(3):e105-12.

30. Lawn SD, Myer L, Edwards D, Bekker LG, Wood R. Short-term and long-term risk of tuberculosis associated with CD4 cell recovery during antiretroviral therapy in South Africa. AIDS. 2009;23(13):1717-25.

31. Lodi S, del Amo J, d'Arminio Monforte A, Abgrall S, Sabin C, Morrison C, Furrer H, Muga R, Porter K, Girardi E. CASCADE collaboration in EuroCoord: risk of tuberculosis following HIV seroconversion in high-income countries. Thorax. 2013;68(3):207-13.

32. Notermans DW, Pakker NG, Hamann D, Foudraine NA, Kauffmann RH, Meenhorst PL, et al. Immune reconstitution after 2 years of successful potent antiretroviral therapy in previously untreated human immunodeficiency virus type 1-infected adults. J Infect Dis. 1999;180:1050-6.

33. Valdez $\mathrm{H}$, Connick E, Smith KY, Lederman MM, Bosch RJ, Kim RS, et al. Limited immune restoration after 3 years' suppression of HIV-1 replication in patients with moderately advanced disease. AIDS. 2002;16:1859-66.

34. Tarwater PM, Margolick JB, Jin J, Phair JP, Detels R, Rinaldo C, et al. Increase and plateau of CD4 T-cell counts in the 3(1/2) years after initiation of potent antiretroviral therapy. J Acquir Immune Defic Syndr. 2001;27:168-75.

35. Smith K, Aga E, Bosch RJ, Valdez H, Connick E, Landay A, et al. Long-term changes in circulating CD4 T lymphocytes in virologically suppressed patients after 6 years of highly active antiretroviral therapy. AIDS. 2004;18:1953-6.

36. Battegay M, Nüesch R, Hirschel B, Kaufmann GR. Immunological recovery and antiretroviral therapy in HIV-1 infection. Lancet Infect Dis. 2006;6(5):280-7.

37. Lawn SD, Bekker LG, Wood R. How effectively does HAART restore immune responses to mycobacterium tuberculosis? Implications for tuberculosis control. AIDS. 2005;19(11):1113-24.
38. Churchyard GJ, Scano F, Grant AD, Chaisson RE. Tuberculosis preventive therapy in the era of HIV infection: overview and research priorities. J Infect Dis. 2007;196(Suppl 1):S52-62.

39. Zumla A, Raviglione M, Hafner R, von Reyn CF. Tuberculosis. N Engl J Med. 2013;368(8):745-55.

40. Lu W, Mehraj V, Vyboh K, Cao W, Li T, Routy JP. CD4:CD8 ratio as a frontier marker for clinical outcome, immune dysfunction and viral reservoir size in virologically suppressed HIV-positive patients. J Int AIDS Soc. 2015;18:20052.

41. Pirzada Y, Khuder S, Donabedian H. Predicting AIDS-related events using CD4 percentage or CD4 absolute counts. AIDS Res Ther. 2006;3:20.

42. Cao W, Mehraj V, Trottier B, Baril JG, Leblanc R, Lebouche B, Cox J, Tremblay C, Lu W, Singer J, Li T, Routy JP. Montreal primary HIV infection study group. Early initiation rather than prolonged duration of antiretroviral therapy in HIV infection contributes to the normalization of CD8 T-cell counts. Clin Infect Dis. 2016:62(2):250-7.

43. Helleberg M, Kronborg G, Ullum H, Ryder LP, Obel N, Gerstoft J. Course and clinical significance of CD8+ T-cell counts in a large cohort of HIV-infected individuals. J Infect Dis. 2015;211(11):1726-34.

44. Schmidt D, Kollan C, Neuhauss AK, Bremer V, Gunsenheimer-Bartmeyer B. Is persistent viremia still an ongoing problem in antiretroviral treatment? DZIF Annual Meeting: German Centre for Infection Research. Cologne: Flora; 2016 [Poster]. Available at: http://www.dzif-annual-meeting2016.de/EN/assets/ book_of_abstracts.pdf. Accessed 24 July 2017.

\section{Submit your next manuscript to BioMed Central and we will help you at every step:}

- We accept pre-submission inquiries

- Our selector tool helps you to find the most relevant journal

- We provide round the clock customer support

- Convenient online submission

- Thorough peer review

- Inclusion in PubMed and all major indexing services

- Maximum visibility for your research

Submit your manuscript at www.biomedcentral.com/submit 